\title{
Trabalho em equipe no contexto da reabilitação infantil
}

I ${ }^{1}$ Alice da Costa Uchôa, ${ }^{2}$ Renata Magalhães Vieira Vieira, ${ }^{3}$ Paulo de Medeiros

Rocha, ${ }^{4}$ Nadja de Sá Dantas Rocha, ${ }^{5}$ Renata Melo Maroto I

Resumo: Este artigo objetiva discutir avanços e desafios do trabalho em equipe multiprofissional na reabilitação infantil. A pesquisa desenvolveu-se num centro de referência estadual, em Natal, RN, Brasil, entre maio e julho de 2010. O método utilizado foi o estudo de caso, com entrevistas semiestruturadas, numa amostra qualitativa de 20 profissionais de saúde de nível superior. Contemplaram-se as categorias: concepção de trabalho em equipe; interação nesta e com família e escola; intercâmbio de conhecimentos e interdisciplinaridade; flexibilidade da divisão do trabalho; integralidade e qualidade da assistência; valorização do trabalho; limites profissionais; e relaçôes interpessoais. Aplicou-se a análise de conteúdo. Os resultados mostraram busca da integralidade e objetivos comuns. Como desafios destacaram-se: falta de projetos assistenciais, protocolos e discussões; dificuldades de interação, integração e delimitação profissional; rigidez na divisão de trabalho. Conclui-se que o trabalho organiza-se numa dimensão instrumental voltada à integralidade e à resolutividade, mas sem integração e reconhecimento mútuo de atuação em equipe.

> Palavras-chave: trabalho em equipe; reabilitação; cuidado; saúde da criança; integralidade.

\author{
1 Médica; mestre em Sociologia \\ (Universidade Federal da \\ Paraíba); doutora em Saúde \\ Coletiva (IMS-UERJ); professora \\ associada (Departamento \\ de Saúde Coletiva, UFRN). \\ Endereço eletrônico: aliuchoa@ \\ hotmail.com \\ ${ }^{2}$ Graduanda do último ano do \\ curso de medicina da UFRN; \\ discente do Grupo de Estudos \\ em Saúde Coletiva da UFRN. \\ Endereço eletrônico: renatam \\ vieira@hotmail.com \\ ${ }^{3}$ Médico; mestre em Medicina \\ (Instituto de Psiquiatria, UFRJ) \\ doutor em Saúde Coletiva \\ (IMS-UERJ); professor associado \\ III (Departamento de Saúde \\ Coletiva da Universidade \\ Federal do Rio Grande do \\ Norte). Endereço eletrônico: \\ paulorocha@digi.com.br \\ ${ }^{4}$ Médica; mestre em Saúde \\ Coletiva (IMS-UERJ); professo \\ assistente IV (Departamento \\ de Pediatria, UFRN). Endereço \\ eletrônico: nadjasadantas@ \\ gmail.com \\ ${ }^{5}$ Enfermeira; mestranda em \\ Saúde Coletiva (Universidade \\ Federal do Rui Grande do \\ Norte). Endereço eletrônico: \\ renatinhamaroto@hotmail.com
}

Recebido em: 25/03/2011 Aprovado em: 31/10/2011. 


\section{Introdução}

Em todos os níveis de atenção à saúde, aumenta a necessidade do trabalho em equipe para alcançar uma abordagem integral sobre os fenômenos que interferem na saúde da população. Sua adoção potencializa a ação interdisciplinar e rompe com uma cultura institucional centrada numa divisão hierarquizada de trabalho na abordagem do processo saúde-doença (AYRES, 2005)

O conceito de reabilitar inclui diagnóstico, intervenção precoce, utilização adequada de recursos tecnológicos, continuidade de atenção, e diversidade de modalidades de atendimentos. Visa à compensação da perda da funcionalidade do indivíduo, à melhoria ou manutenção da qualidade de vida e à inclusão social (RIBEIRO, 2010). Para Coelho e Lobo (2004), o trabalho de reabilitação deve englobar tanto o aspecto técnico quanto o da cidadania da pessoa com deficiência, que tem o direito de fazer escolhas e de ser a autora de sua própria história.

No Brasil, a reabilitação compõe uma das linhas do cuidado que integra a agenda nacional prioritária da saúde da criança. O principal objetivo da reabilitação da criança é o de desenvolver a reaprendizagem de habilidades e a elaboração de planos de tratamento para amenizar ou compensar as funções afetadas em relação às demandas do ambiente familiar e escolar (SOUSA; CANDEIAS, 2005).

Embora não estejam claros quais componentes do trabalho em equipe melhoram a resposta funcional dos pacientes, este tem sido considerado o modelo de escolha para atuação em reabilitação (BAKHEIT, 1996). É possível perceber que metas da reabilitação serão mais fáceis de serem alcançadas por meio de esforços tanto intersetorial quanto multiprofissional. Esse esforço ajudará a superar as dificuldades sentidas pelos profissionais na medida em que as complicações no estado de saúde da criança acabam demandando diversos especialistas, como fonoaudiólogos, fisioterapeutas, terapeutas ocupacionais, nutricionistas e psicólogos, que se complementam no apoio à criança com necessidades especiais (SILVA; DAMIANE,2003).

Considerandoas várias configuraçōes do trabalho em equipe-multiprofissional, pluridisciplinar, multidisciplinar, interdisciplinar, transdisciplinar (LESSARD; MORIN; SYLVAIN, 2008)-, e reconhecendo a complexidade epistemológica e metodológica envolvida nessas diversas concepçōes, o presente artigo focaliza a abordagem de equipe multiprofissional do tipo integração com vocação interdisciplinar (PEDUZZI,2001,2007). 
Peduzzi $(2001$; 2007) conceitua o trabalho em equipe como uma modalidade

de trabalho coletivo, em que se configura a relação recíproca entre as intervenções técnicas e a interação dos agentes. A autora toma como base a teoria do agir comunicativo de Jürgen Habermas, destacando a dimensão da intersubjetividade do trabalho (HABERMAS, 1989).

A equipe multiprofissional tem sido avaliada como uma alternativa para lidar com a crescente especialização na saúde que tende a aprofundar o conhecimento e distanciar os profissionais com as mais distintas capacitaçooes (PEDUZZI, 2007). Todavia, ainda enfrentam-se dificuldades para superar as diferenças técnicas e a desigual valoração social dos trabalhos especializados, cujo enfretamento exige uma recomposição dos diferentes processos de trabalho de modo a integrar e preservar as diferenças e especificidades (MEIRELLES, 2003).

Para uma melhor compreensão dessa recomposição, os conceitos de núcleo e campo, discutidos por Campos (2000), são úteis no sentido de combinar a necessidade de polivalência e responsabilização, e conciliar autonomia com responsabilidade. O núcleo se refere ao conjunto de saberes e de responsabilidades específicos de cada profissão ou especialidade. A noção de campo comporta saberes e responsabilidades comuns e confluentes às várias profissóes ou especialidades. Assim, o trabalho em equipe não propõe abolir as especificidades dos trabalhos, pois as diferenças técnicas podem contribuir para a melhoria dos serviços prestados e maior capacitação profissional. Os profissionais devem estar aptos a realizar intervenções próprias de suas respectivas áreas, e executar ações comuns, nas quais estão integrados saberes de distintos campos como recepção, acolhimento, grupos educativos, grupos operativos, entre outros (PEDUZZI, 2007).

Essa forma de trabalho traz diversos benefícios; dentre eles, a possibilidade de formar uma rede de relações entre as pessoas, rompendo a visão dominante e individualista das especialidades, permitindo manter uma união e troca de ideias, saberes, vontade e trabalho voltados às práticas inovadoras. Propicia-se uma melhor organização do serviço e a adoção do respeito, autonomia e vínculo entre profissionais e usuários, visando a uma abordagem integral e resolutiva com intervenções multiprofissionais diferenciadas.

Queiroz e Araújo (2006) consideram central o processo de decisão no trabalho em equipe na reabilitação, tanto no plano individual quanto no coletivo. Esse processo é complexo e problemático em decorrência da 
diversidade de informações que devem ser processadas e negociadas para identificar os possíveis cursos de ação nos diferentes níveis. Assim, a maneira como os profissionais tomam decisões e como o grupo é afetado por elas é relevante para compreender o impacto do trabalho em equipe nos cuidados do paciente e na conduta desta (COOK et AL, 2001).

Estudos sobre os sentimentos e percepções da equipe de saúde frente ao paciente terminal reafirmam que ainda é necessário incrementar os conhecimentos sobre os processos subjacentes ao trabalho em equipe de saúde (QUEIROZ; ARAÚJO, 2007; QUINTANA et al, 2009).

Este artigo tem como objetivo avaliar os avanços e desafios do trabalho em equipe multiprofissional no contexto da reabilitação infantil e da integralidade do cuidado, apreendido por seu aspecto relacional, uma interação entre sujeitos equipe de saúde e usuários/família no processo de atenção à saúde (PINHEIRO, 2007). O sentido da integralidade apontado é o da dimensão das práticas dos profissionais de saúde, que devem incorporar nas respostas terapêuticas não apenas o ponto de vista biológico, mas também o emocional e o social (PINHEIRO; MATTOS, 2004), onde o trabalho em equipe ocupa um lugar central.

\section{Metodologia}

Trata-se de um estudo de caso de cunho etnográfico (BECKER, 1999). O trabalho de campo ocorreu em Natal, Rio Grande do Norte, Brasil, no centro de referencia estadual para reabilitação da saúde infantil (CRI) entre maio e julho de 2010.

Segundo dados da Secretaria Estadual de Saúde Pública, o centro foi criado em 1990, e realiza, em média, 12 mil atendimentos mensais a crianças e adolescentes de 0 a 18 anos portadores de deficiências físicas, mentais, sensoriais ou múltiplas, prestando serviços na área médico-ambulatorial, em estimulação precoce e reabilitação, contando com 57 profissionais de saúde

Para população de estudo foram considerados elegíveis 38 profissionais a partir dos seguintes critérios: possuir nível superior e ser responsável diretamente pela atenção à saúde das crianças. Destes, 18 profissionais foram excluídos: por recusa à participação (5), por afastamento (5) e por participarem do teste piloto (8). Esses procedimentos resultaram numa amostra de 20 sujeitos, sendo quinze do sexo feminino e cinco do masculino, e a seguinte distribuição: dez médicos, 
três dentistas, três assistentes sociais, um enfermeiro, uma nutricionista, um psicólogo e uma fisioterapeuta.

A técnica utilizada foi entrevista com roteiro semiestruturado. Após o testepiloto, procedeu-se ao ajuste do instrumento. As entrevistas foram gravadas e transcritas, e tiveram duração média de 1 hora. $\mathrm{O}$ roteiro contemplou categorias previamente escolhidas com base no referencial teórico adotado e categorias pós-campo: concepção de trabalho em equipe; interação entre os membros da equipe; interação com família e escola; Intercâmbio de conhecimentos e interdisciplinaridade; flexibilidade da divisão do trabalho; integralidade e qualidade da assistência; valorização do trabalho dos profissionais da equipe; reconhecimento de limites no exercício profissional e nas relações interpessoais.

Utilizou-se a análise de conteúdo (BARDIN,1979). A primeira etapa foi a pré-análise, que se apoiou numa leitura flutuante das transcrições e anotações empreendidas. Seguiu-se à descrição analítica, na qual, com base no referencial teórico e em diversas leituras do material obtido (imersão), organizou-se o material nas categorias de análise.

A pesquisa foi aprovada no Comitê de Ética em Pesquisa do Hospital Universitário Onofre Lopes, da Universidade Federal do Rio Grande do Norte sob protocolo $419 / 10$.

\section{Resultados e discussão}

\section{Concepção sobre trabalho em equipe}

Quanto à sua concepção, identificou-se na fala dos profissionais o trabalho em equipe como aquele em que cada membro da equipe participa do cuidado com seus conhecimentos específicos, sendo coordenado por diversos setores e especialidades com vistas a alcançar o mesmo objetivo. Observa-se, ainda, a ideia de "ajuda" ao paciente.

Um trabalho no qual a gente consegue ajudar a pessoa e tem o objetivo, no caso da saúde, de proporcionar uma melhoria na saúde do paciente. E essa equipe é importante porque cada um tem seu ponto de participação dentro dessa patologia. Quando eu atendo meu paciente, eu preciso saber como ele está, ao lado da atenção médica, do psicólogo. [Entrevistado S]

Ressaltou-se, ainda, a importância da interação e da integração como demarcadores da equipe: 
[...] trabalho em equipe para mim não é só um grupo de pessoas que trabalham no mesmo lugar; é um grupo de pessoas que trabalham e interagem, trocam informaçôes, trocam sugestôes, que se auxiliam. Ter várias pessoas atendendo numa mesma instituição não significa ter trabalho em equipe. (Entrevistado F).

Assim como no estudo de Queiroz e Araújo (2009), houve predominância de depoimentos com referencia às categorias profissionais específicas (composição) e objetivos comuns (funções da equipe), havendo pouco foco na integração, no paciente e na família. O alcance de objetivos comuns explicita a percepção da dimensão do agir instrumental presente em muitas esferas da reabilitação. Com relação aos pacientes, estes surgem nas falas como fonte de informação e objetivo do trabalho. Deve-se ressaltar que, embora o paciente deva ser incluído na equipe, deve-se considerar que os déficits cognitivos enfrentados por alguns muitas vezes comprometem sua participação.

Mesmo que muitos componentes do conceito de trabalho em equipe estivessem presentes no discurso dos profissionais do CRI, estes admitem que ele não ocorre na prática:

Sinceramente, não, pois aqui não existe um compromisso com a integração. [Entrevistado E]

Apesar de a gente contar com uma gama muito grande de profissionais, o que existe aqui é um esquema de consulta. [Entrevistado C]

Alguns profissionais, apesar de falarem da inexistência do trabalho em equipe, fizeram ressalvas:

[...] não é um trabalho em equipe como deveria, mas quando nos deparamos com um quadro que necessita de maior contato da equipe, a gente procura desenvolver esse tipo de trabalho. [Entrevistado D]

Pelos depoimentos, observa-se que a organização do trabalho na perspectiva de trabalho em equipe só acontece em situações nas quais haja a necessidade do cuidado multiprofissional; porém, isso não garante uma interação efetiva entre os profissionais. Ou seja, a situação trazida pelos pacientes pode mobilizar esse tipo de ação.

\section{Interação entre os membros da equipe}

A maioria dos entrevistados admite a importância da formulação de projetos assistenciais comuns na promoção da interação entre os membros da equipe. 
Todavia, na prática cotidiana, sua ocorrência é pouco sistemática e por parte de poucos profissionais:

[...] existe, mas infelizmente não é sistemático; a gente acaba percebendo, no dia-adia, que não dá conta de fazer esse trabalho que a gente se propõe. [Entrevistado B].

[...] já aconteceu, mas por iniciativa de um ou dois profissionais, que aí buscam os outros. Os outros, então, dão a sua colaboração nesse sentido, mas a tendência sempre é que o andamento do projeto pare por falta de interesse. [Entrevistado $\mathrm{H}$ ].

$\mathrm{O}$ uso de protocolos era associado a algumas categorias profissionais, como o serviço social, enfermagem e odontologia. Apenas um profissional relatou fazer uso cotidiano deles, e de forma descontínua devido à grande demanda de atendimentos na instituição.

Essa grande demanda e a exigência de produtividade por parte da Secretaria Estadual de Saúde foi referida por vários entrevistados como fatores mais limitantes do processo de trabalho em equipe e favoráveis às ações isoladas dentro das áreas especializadas.

$\mathrm{Na}$ maioria das vezes, a comunicação sobre o estado de saúde e as condutas ficava restrita à leitura das folhas de evolução dos prontuários. Mesmo assim, ela era efetuada apenas por alguns profissionais. Praticamente não havia planejamento local, e o plano de trabalho era determinado pela secretaria.

Silva e Trad (2005) constatam que a necessidade de responder às demandas do nível central impede que as ações programáticas sejam colocadas em prática. $\mathrm{O}$ grande número de atividades de cada profissional faz com que, ao longo do tempo, o trabalho se torne mais fragmentado.

\section{Interação com a família e escola}

No que se refere ao contato da equipe de saúde com os pais, a maior parte dos entrevistados ressaltou que, ao longo de seus atendimentos, mantém uma boa comunicação, tentando explicar-lhes individualmente a doença, o que esperar em termos de prognóstico e quais condutas estão sendo adotadas:

A comunicação com os pais é um processo que se dá de forma individualizada. Eu acho que cada profissional, dentro de suas limitaçôes técnicas, tem feito isso. [Entrevistado C].

A comunicação com a escola, por outro lado, é praticamente nula. A realização de atividades em grupo com as crianças e com os pais é inexistente. Apenas 
os profissionais da odontologia afirmaram haver, anualmente, uma semana dedicada à higiene oral, com distribuição de escovas de dente e demonstração de escovação correta, mesmo assim sem apoio da gerência:

[...] em geral, uma vez por ano, na semana do dia do dentista, organizamos um evento para incentivar a escovação. Nós, por iniciativa própria, conseguimos doaçōes de escovas de dente e pasta. Não contamos com nenhum apoio da direção, que na maior parte das vezes, não vem nem assistir. [Entrevistado E]

As atividades lúdicas grupais para as crianças se restringem às comemorações em datas específicas, como dia das crianças, São João e Natal, e contam com a participação de todos os profissionais da instituição.

\section{Intercâmbio de conhecimentos e interdisciplinaridade}

Sobre a troca de saberes entre os membros da equipe, os profissionais entrevistados foram quase unânimes ao afirmar que as reuniōes científicas estavam desatualizadas, descontínuas e pouco interativas:

Acho que deveria haver até mais interação e ser mais contínuo. [Entrevistado D]

Embora, muitos tenham ressaltado a importância do intercâmbio de conhecimentos, eles deixaram claro que isso não vem ocorrendo nas sessões de estudo de caso. Nessas ocasiōes, o profissional apresentava o caso clínico de algum paciente com o qual estivesse em contato e expunha a sua conduta, sem que houvesse uma discussão participativa entre os membros da equipe de trabalho:

[...] o estudo de caso daqui, não é estudo de caso. O estudo de caso era pra "pegar" um paciente e ver como vamos trabalhar com ele. O que ocorre é que a gente apresenta o que está fazendo com o paciente. [Entrevistado E]

Outra crítica constante foi o uso do espaço e horário destinados às reuniões científicas para a discussão e resolução de temas administrativos:

[...] nem todos os meses são apresentados casos, porque, às vezes, é necessário apresentar algumas mudanças na Secretaria de Saúde, como foi o caso dessa última. [Entrevistado D]

[...] foge muito da realidade, porque chega até ao ponto de se resolver problema administrativo nessas reuniōes. [Entrevistado E]

Diferentemente dos resultados do presente estudo, no trabalho de Matos e Pires (2009), as reuniōes semanais da equipe eram voltadas à integração interdisciplinar e ao gerenciamento do trabalho coletivo, possibilitando uma visão mais global 
do doente e o estabelecimento de planos de cuidados mais próximos das suas necessidades. Nessas reuniōes, a equipe também abordava questões administrativas e acrescentava: estudo de caso clínico, atualização profissional, planejamento das atividades assistenciais, discussões de projetos, e outros tópicos. $\mathrm{Na}$ maioria das vezes, os profissionais discutiam as ações propostas até entrarem em consenso.

Pelos relatos dos profissionais do centro, a prática de interconsultas ocorria usualmente, mas com algumas limitações, principalmente o pouco tempo disponível também devido à grande demanda de pacientes:

[...] o entrave é que, normalmente, o colega não tem disponibilidade de tempo, sendo, às vezes, uma comunicação rápida, não o tanto quanto eu gostaria que fosse, sobretudo quando são situaçôes que precisam de algo mais aprofundado. [Entrevistado C]

Especificamente com os médicos a interconsulta era considerada mais difícil por estes dificilmente cumprirem o horário de trabalho deixando a instituição imediatamente após os atendimentos diários.

\section{Flexibilidade na divisão do trabalho}

Foi verificado nas entrevistas que a divisão do trabalho não ocorria de maneira satisfatória. Atividades comuns, passíveis de serem realizadas pelos diferentes profissionais como acolhimento, eram realizadas por agentes isolados e não capacitados:

[...] eu acho que as pessoas que estão à frente da recepção não são as pessoas que deveriam estar lá ou então, que elas precisam se reciclar. [Entrevistado B].

O acolhimento também era feito pelo Serviço Social e criticado por não conseguir explicar o funcionamento da instituição aos novos pacientes e repassarlhes seus direitos e deveres. Não houve referencia à humanização inerente ao acolhimento, inclusão de outros profissionais, e triagem com priorização de riscos.

\section{Integralidade e qualidade da assistência}

Para os profissionais, a assistência prestada é percebida pelas famílias como satisfatória:

A reação é sempre favorável. Raramente, ouvimos alguma reclamação. (Entrevistado F).

As principais queixas referidas são as longas listas de espera para o início do tratamento e as dificuldades na marcação de consultas e retornos para algumas especialidades, como neurologia e neuropediatria. As falas revelam problemas de 
acesso ao serviço e de integração de uma rede de cuidados especializada, na qual, supostamente, esses profissionais deveriam fazer parte da equipe de trabalho pela natureza dos problemas de saúde a serem enfrentados.

Apesar desses problemas e daqueles relativos à infraestrutura, como equipamentos em falta ou quebrados, os profissionais declaram que mesmo com limitações conseguem o objetivo de uma assistência voltada às necessidades das crianças. Há o empenho de abordar o problema da criança no seu primeiro contato com a instituição por meio do atendimento ambulatorial, fornecendo orientações para serem executadas pelas famílias de modo a minimizar os problemas mesmo antes da admissão no setor de reabilitação.

[...] acho que a reabilitação já ocorre desde o início, porque quando as crianças passam pelos profissionais daqui, eles já vão orientando. Então, muita coisa já vai sendo trabalhada. Até porque a gente sabe que há lista de espera para quase todos os atendimentos e que muito raramente o paciente deixa o Ambulatório e já inicia imediatamente o tratamento na Reabilitação. Desse modo, a gente já procura dar um suporte para que as coisas tendam a ir caminhando. [Entrevistado F]

Também são valorizados aspectos emocionais relacionados, diretamente ou não, às patologias, revelando uma percepção de necessidade de saúde mais abrangente, o que gera uma perspectiva mais integralizada das ações:

[...] destaco, por exemplo, os casos de crianças com problemas na dentição, que embora tenham déficits cognitivos, têm alguma "luz" e conseguem perceber o que está feio, e acabam com nítido comprometimento psicológico. O trabalho que fazemos aqui na Odontologia consegue a reparação dessas condiçôes e muitas vezes as mães nos contam que fazia tempo que não viam suas crianças dando um sorriso. [Entrevistado E]

\section{Valorização do trabalbo dos demais profissionais}

Os profissionais revelaram que os membros da equipe se valorizam mutuamente, por julgarem que todas as categorias profissionais são importantes no processo de triagem das crianças ingressantes na instituição.

[...] acho que todas as categorias são importantes, até porque, para o haver o trabalho em equipe, cada um tem de ter o seu papel, e todos se completam. [Entrevistado A]

[...] acho muito importante essa integração e interação exatamente porque eu valorizo o trabalho do outro. Eu tenho um conhecimento que não é suficiente para fazer aquele serviço naquela área, então daí a importância de, nesse processo de reabilitação, todos andarem de mãos dadas. [Entrevistado C] 
Apenas um profissional teve opinião discordante:

No setor, percebo que, de uma maneira geral, as categorias pensam muito isoladamente. Não há uma preocupação com o todo. [Entrevistado E]

Quanto ao conhecimento do trabalho dos demais profissionais, os entrevistados ressaltaram que têm a preocupação de se informar sobre a área de atuação e prática profissional dos demais:

Todos os profissionais têm essa preocupação, até porque você não pode encaminhar o paciente para uma pessoa e não saber o que ela vai fazer. [Entrevistado F].

Alguns profissionais procuraram enfatizar a importância das reuniōes científicas nesse aspecto, e também de que forma elas contribuem para o conhecimento do trabalho dos membros da equipe:

[...] tiveram uns estudos de caso nos quais os profissionais apresentaram o seu trabalho e isso foi muito interessante, pois acabou ajudando para que nos conhecêssemos melhor o que o outro faz. [Entrevistado A].

\section{Reconhecimento dos limites no exercício profissional}

Uma das dificuldades abordadas pela grande maioria foi o fato de haver limites pouco precisos no exercício profissional, dando margem à ocorrência de inúmeras interferências na prática diária.

[...] alguns profissionais entram na área do outro e fornecem informaçōes erradas. Com o dia-a-dia, eu já consegui até melhorar essa situação, mas não deixa de haver invasões.

É difícil, pois precisa muito que cada um saiba o seu limite e respeite. [Entrevistado D].

No entanto, alguns profissionais enfatizaram certos aspectos que demonstram uma maior preocupação com o trabalho em equipe:

[...] Eu vejo da seguinte forma: se você trabalha em equipe e o mais importante é o paciente, eu não vejo o porquê desse ego todo, desses brios todos, quando alguém tem a iniciativa e parte na dianteira. Pode ser até que seja um conceito errado meu, mas dentro do trabalho em equipe, eu não vejo essa necessidade de estar policiando o outro e se policiando. [Entrevistado C]

[...] Eu não vejo invasão, não. O que eu vejo muitas vezes e acho extremamente salutar, e adoraria que houvesse mais, é o trabalho transdisciplinar. Porque na comunicação com outros profissionais, compartilhando idéias e sugestôes a cerca de um caso, não há invasão, há troca. Por exemplo, eu não sou fonoaudióloga, mas eu posso conversar com o profissional e repassar algumas orientações às mães, enquanto a criança ainda não está sendo atendida por esse profissional. [Entrevistado F] 
Resultado similar foi observado em entrevistas de profundidade realizadas por Pinho (2006). Constatou-se que, embora haja um consenso da equipe no sentido de que ações técnicas pertinentes a cada área profissional estão bem definidas, cabendo a cada uma determinadas tarefas bem específicas, existem algumas situações nas quais essas fronteiras não estão bem delimitadas, causando certo desconforto quando o espaço do especialista é invadido.

\section{Relações interpessoais}

Os entrevistados do centro de referência foram categóricos ao afirmar que o convívio na instituição é muito bom:

[...] há um bom relacionamento, até porque a grande parte dos profissionais que está aqui, já está há bastante tempo. Então, todos já se conhecem bem e cada um sabe o estilo de profissional com o qual está lidando. [Entrevistado F]

É possível perceber que os sujeitos idealizam o trabalho em equipe como aquele que tem uma dinâmica constantemente harmônica e homogênea. Comumente, as equipes projetam as relações, que devem ocorrer como um trabalho de cooperação e colaboração ampla e incondicional, sem desentendimentos e com crescimento irrestrito de todos os seus componentes.

Esse tipo de percepção prevalece quando há grande medo da equipe em admitir a existência de conflitos comuns na convivência grupal. Todavia, diversos autores têm demonstrado que o conflito faz parte do trabalho em equipe.

\section{Considerações finais}

Os resultados desta pesquisa possibilitaram a elaboração de análises mais específicas sobre o trabalho em equipe no CRI, com a ampliação de conhecimentos sobre o tema.

Reafirma-se que o trabalho em equipe representa a possibilidade de integralidade no cuidado no nível de reabilitação infantil. Para uma melhor compreensão, essas análises elaboradas na pesquisa foram sistematizadas, à guisa de conclusões.

A unidade de análise principal da pesquisa - avaliar os desafios do trabalho em equipe multiprofissional no contexto da reabilitação infantil - permitiu ao final do estudo reconhecer na realidade estudada o predomínio da equipe do tipo agrupamento apresentado nos estudos de Peduzzi (2001; 2007). Porém, o 
reconhecimento do respeito às fronteiras disciplinares e a valorização das demais categorias profissionais, a compreensão do trabalho em equipe como união de esforços para o alcance de um objetivo comum com a atenção integral do cuidado podem aproximar essa equipe da imagem-objetivo da equipe integração.

Ao olhar para o cotidiano do CRI observa-se que, embora a equipe seja multiprofissional na sua composição, a falta de interdisciplinaridade foi demonstrada pela carência quanto à formulação de projetos assistenciais comuns e o uso de protocolos compartilhados. Diversos fatores foram apontados como limitantes para que a interação se processasse entre os profissionais, dos quais se destacam a grande demanda de pacientes e a falta de incentivo do órgão gestor e da própria direção da instituição para a prática profissional em equipe.

A articulação de ações e a troca de conhecimentos e saberes entre os profissionais que contribuiriam para interdisciplinaridade são pontos igualmente defasados.

A prática de interconsultas foi a única atividade referida como comum entre os entrevistados. No entanto, dificuldades foram destacadas para o seu processamento, como a pouca disponibilidade de tempo dos profissionais, devido ao grande número de atendimentos diários, e o não cumprimento dos horários de expediente por alguns profissionais, que deixam a instituição tão logo finalizam seus atendimentos.

A falta de interação e integração entre os profissionais da instituição acaba se refletindo em uma divisão de trabalho pouco flexível.

A incorporação de novas tecnologias de trabalho, como as reuniōes técnicas, espaço favorável à integração e a interdisciplinaridade, representa, na realidade, momento de repasse de informes administrativos, não havendo portanto, a criação de canais de comunicação (espaços coletivos) para discussão conjunta dos problemas, o que significa que não se estabelece com a equipe uma relação de interação.

Apesar de todos os pontos que comprometem a existência do trabalho em equipe na instituição e dos desafios enfrentados (a falta de projetos assistenciais, protocolos e discussão ampliada dos casos; rigidez na divisão de trabalho; dificuldades de delimitação na atuação profissional), perceberam-se alguns avanços, como a perspectiva da incorporação da integralidade dos cuidados e da qualidade da assistência como objetivos, e a percepção da necessidade de integração como forma de alcançá-lo. 
A partir dessas primeiras considerações, ressalta-se, nitidamente, a necessidade de pesquisas sobre equipe de saúde; mas, agora, aprofundando e especificando as análises sobre as equipes nos espaços de reabilitação, isso se justifica por suas características fortemente contextuais e de uniformização de concepções e práticas, com suas possibilidades, limitações e articulações, em microespaços concretos, específicos ${ }^{1}$.

\section{Referências}

AYRES, J.R.C.M. Cuidado e reconstrução das práticas de saúde. In: MINAYO, M.C.S.; COIMBRA JR., C.E.A. (Orgs.). Críticas e atuantes: ciências sociais e humanas em saúde na América Latina. Rio de Janeiro: Fiocruz, 2005. p.91-108.

BAKHEIT, A.M.O. Effective teamwork in rehabilitation. International Journal of Rehabilitation Research, v.19, p.301-6, 1996.

BARDIN, L. Análise de conteúdo. Lisboa: Edições 70, 1979.

BECKER, H. Métodos de Pesquisa em Ciências Sociais. São Paulo: Hucitec, 1999.

CAMPOS, G.W.S. Saúde pública e saúde coletiva: campo e núcleo de saberes e práticas. Ciência e. Saúde Coletiva, v.5, n.2, p.219-230, 2000.

COELHO, A.E.B.D.; LOBO, S.T. Gestão participativa na organização de uma rede de reabilitação em saúde pública. Rev Virt Gestão Iniciat Soc., v.1, p.37-45, out 2004.

COOK, G.; GERRISH, K.; CLARKE, C. Decision-making in team: Issues arising from two UK evaluations Journal of Interprofissional Care, v.15, n.2, p.141-145, 2001.

HABERMAS, J. Consciência moral e agir comunicativo. Rio de Janeiro: Tempo Brasileiro, 1989. LESSARD, L.; MORIN, D.; SYLVAIN, H. Understanding teams and teamwork. Canadian Nurse, v. 104, n.3, p. 12-13, 2008.

MATOS, E.; PIRES, D.E.P. Práticas de cuidado na perspectiva interdisciplinar: um caminho promissor. Texto e Contexto Enfermagem, v.18, p.338-46, 2009.

MEIRELLES, B.H.S. Viversaudávelem tempos de Aids: a complexidade e a interdisciplinaridade no contexto de prevenção da infecção pelo HIV [tese]. Florianópolis: Programa de PósGraduação em Enfermagem, Universidade Federal de Santa Catarina; 2003.

PEDUZZI, M. Equipe multiprofissional de saúde: conceito e tipologia. Revista de Saúde Pública, v. 35, p.103-9, 2001.

. Trabalho em equipe de saúde no horizonte normativo da integralidade, do cuidado e da democratização das relações de trabalho. In: PINHEIRO, R.; MATTOS, R.A.; BARROS, M.E.B. (Org.). Trabalho em equipe sob o eixo da integralidade: valores, saberes e práticas. Rio de Janeiro: Cepesc, 2007. 
PINHEIRO, R. Cuidado como valor: um ensaio sobre o (re)pensar e a ação na construção das práticas de saúde. In: PINHEIRO, R.; MATTOS, R.A. (Org.). Razôes públicas para a integralidade em saúde: o cuidado como valor. Rio de Janeiro: Cepesc, 2007.

PINHEIRO, R.; MATTOS, R.A. Cuidado e integralidade: vida, conhecimento, saúde e educação. In: PINHEIRO, R.; MATTOS, R.A. (Org.). Cuidado: as fronteiras da integralidade. Rio de Janeiro: Cepesc, 2004.

PINHO, M.C.G. Trabalho em equipe de saúde: limites e possibilidades de atuação eficaz. Ciência \& Cognição, v.8, p.68-87, 2006.

QUEIROZ, E.; ARAÚJO, T.C.C.F. Tomada de decisão em equipe de reabilitação: Questôes específicas relativas à assistência e à pesquisa. Revista da Sociedade Brasileira de Psicologia Hospitalar, v.9, n.1, p.3-13, 2006.

- Trabalho de equipe em reabilitação: um estudo sobre a percepção individual e grupal dos profissionais da saúde. Paidéia, v.19, p.177-87, 2009.

. Trabalho em equipe: Um estudo multimetodológico em instituição hospitalar de reabilitação. Revista Interamericana de Psicología, v.41, p.221-230, 2007.

QUINTANA, A.M. et al. Sentimentos e percepções da equipe de saúde frente ao paciente terminal, Paideia Ribeirão Preto, v.16, p.415-425, 2006.

RIBEIRO, C.T.M. et al. O sistema público de saúde e as ações de reabilitação no Brasil. Revista Panamericana de Salud Publica, v.28, p. 43-8, 2010.

SILVA, A.P.; DAMIANI, M.L.B. Importância da adesão do cuidador no tratamento da disfagia neurogênica sob os pontos de vista da Fonoaudiologia e da Psicologia. In: JACOBI, J.S.; LEVY, D.S.; SILVA, L.M.C. (Eds.). Disfagia: avaliação e tratamento. 1ed. Rio de Janeiro: Revinter, 2003. p.101-11.

SILVA, I.Z.Q.J.; TRAD, L.A.B. Team work in the PSF: investigating the technical articulation and interaction among professionals. Interface: Comunicação, Saúde, Educação, v.9, p.25-38, 2005.

SOUSA, C.S.; CANDEIAS, A. A colaboração intersectorial e multiprofissional na intervenção com crianças com necessidades especiais. Revista Educação, v.55, p.11-30, 2005.

\section{Nota}

${ }^{1}$ A.C. Uchoa trabalhou na concepção, análise, interpretação dos dados, revisão crítica e redação final do texto; P.M. Rocha e R.M. Vieira trabalharam na metodologia, interpretação dos dados e revisão crítica do texto; R.M. Maroto e N.S.P.D. Rocha trabalharam na interpretação dos dados, revisão crítica e redação final do texto. 


\section{Multiprofessional teamwork in child rehabilitation}

This paper aims to discuss advances and challenges of multiprofessional teamwork in child rehabilitation. The study was conducted in a state reference center, in Natal, Brazil, between May and July 2010. This is a case study using semi-structured interviews with a qualitative sample of 20 upper level health professionals. Three categories were considered: conception of teamwork; interaction with the team, family and school; exchange of knowledge and interdisciplinarity; flexibility in division of work; integrality and quality care; work values; professional limits and interpersonal relationships. Content analysis was applied. In relation to advances, professionals underscore common objectives and the search for integrality. The following challenges were cited: lack of assistance programs, protocols and discussions; interaction, integration and professional delimitation difficulties; and strict division of work. Work is organized into an instrumental dimension directed towards integrality and resoluteness, but without interaction and mutual recognition of teamwork.

Key words: teamwork; rehabilitation; care; child health; integrality. 